\title{
Determination of the Parameters of Geomechanical Stress Undulation Along the Length of a Face
}

\author{
Maksim Shinkevich ${ }^{1,2}$, Leonid Shevchenko ${ }^{1}$, and Valery Grishin ${ }^{3}$ \\ ${ }^{1}$ T.F. Gorbachev Kuzbass State Technical University, 65000028 Vesennya st., Kemerovo, Russian \\ ${ }^{2}$ Institute of Coal of the Federal Research Centre of Coal and Chemistry Siberian Branch of Russian \\ Academy of Science, 650065, Kemerovo, Russia \\ ${ }^{3}$ Ministry of Energy of the Russian Federation, 107996 GSP-6, Moscow, Russia
}

\begin{abstract}
The use of the mass structuring flowchart will make it possible to forecast the methane release when mining a coal seam, to determine in advance and reasonably areas of increased rock pressure on a coal seam and a powered support. It will allow forecasting the areas of the negative rock pressure effect along the length of a face, increasing coal mining performance due to a more accurate calculation of the load on a stope and the cutting machinery output, correcting the force of the working bodies of cutting machines when destructing a coal seam, selecting face supports according to their bearing capacity, planning measures to eliminate the negative rock pressure effect in these areas, strengthen a selvedge to reduce the visible coal sloughing. Coal mining performance and safety will increase.
\end{abstract}

\section{Introduction}

The consequences of rock pressure along the length of a face in the form of coal sloughing and changes in cutting resistance of the mined coal seam are discussed in the article. The wave-like behavior of geo-mechanical stresses acting on a coal seam along the length of a face, when it is worked out using longwall mining system, is determined, which is confirmed by fluid pressure in powered support props and the changes in the volume of coal sloughed from a face. The correspondence of the observed features of the response of a coal seam and pressure in the powered support props to the geo-mechanical process flowchart in the robbed-out mass is noted. It is proposed to use the concepts of the mass structuring flowchart to determine the parameters of geo-mechanical stress undulation along the length of a face.

\section{Materials and Methods}

In recent decades, the productivity of pillar taking areas has increased significantly. The trend in increasing the depths of mining, an increase in gas content of the mined coal seams raises issues of maintaining the coal production and further productivity growth. There is no doubt that the main factors militating against the coal mining efficiency are rock pres- 
sure and gas factor. Advances in coal mining machinery and technologies are impossible without taking into account modern knowledge of the processes arising in rock mass during mining. Many scientists, both in Russia [1,2] and abroad [3-7], are engaged in the coal mining safety research. As is known [8], the processes of rock movement and gas release from rock mass are closely interrelated.

Consideration of the processes of rock pressure generation and the corresponding methane release are currently of indisputable relevance.

In $[8,9]$, the wave-like behavior (nonlinearity) of a geo-mechanical process was proved with reference to the coal seam being worked out by longwall system. The conclusions about the non-linearity of geo-mechanical processes are based on the use of mine gas dynamics methods. The nonlinearity of the change in methane content of pillar taking area with a period disproportionately greater than the main roof-caving increment is shown. The data on pressure in powered support props are given [9], which also confirm the undulation process, but the bottom-hole zone of rock mass and possible consequences of the undulating rock pressure are not considered in detail. The data on pressure in powered support props is also mentioned by foreign authors [10]. The undulating character of the pressure change is noted, but also no recommendations are given on the practical application of the observed changes in rock pressure. It all comes down to a statement of noted features.

\section{Results and Discussion}

The studies of the rock pressure effect on a coal seam along the length of a stope [11-14] are also known. The loose of coal mass destructed by cutting machine is considered, which also varies in an undulating mode along the length of a face $[11,12]$. So, in the article [11] the change in the volume of coal sloughed along the length of a face is considered (Fig. 1).

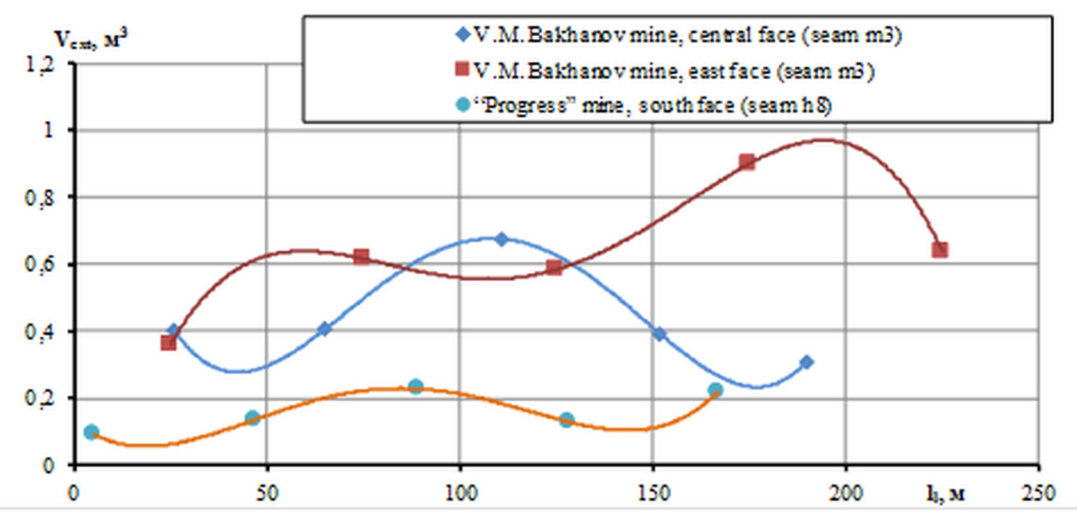

Fig. 1. The change in the volume of coal sloughed along the length of a stope.

From figure 1 it can be seen that the volume of coal sloughed along the length of a stope changes in waves. I.e. rock pressure acting on a coal seam also has an undulation character. In [9], the undulating change in rock pressure is explained by the anthropogenic structuring of rock mass when mining a coal seam.

Based on the results of experimental mining, the parametric model of the formation and the development of de-stressed rock mass zones during face advance, when using longwall mining system, was developed. Its main parameter is the stope length. Other geometrical dimensions are multiples of 2 . The model summarizes the features of the formation of zonal disintegration of mass ahead of the stope and the hierarchy of geo-mechanical layers in the 
worked-out space (Fig. 2) and allows forecasting various manifestations of rock pressure, both during design and during mining.

According to the model, rock mass, in the area of developing geo-mechanical processes, is presented as a set of geo-mechanical layers. For a visual explanation of the arch hierarchy nesting and development, a three-dimensional diagram was built in AutoCAD (Fig. 2, a) and the layout was created (Fig. 2, b).

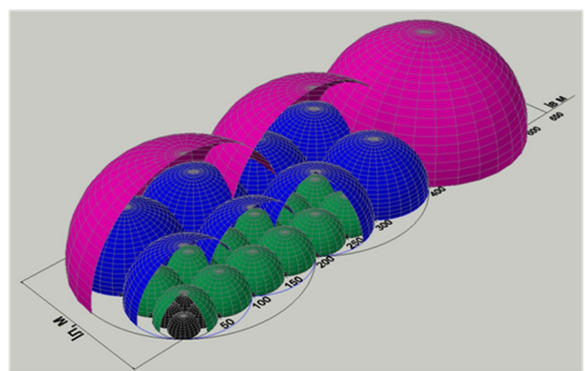

a) three-dimensional diagram of the robbed rock geo-mechanical process

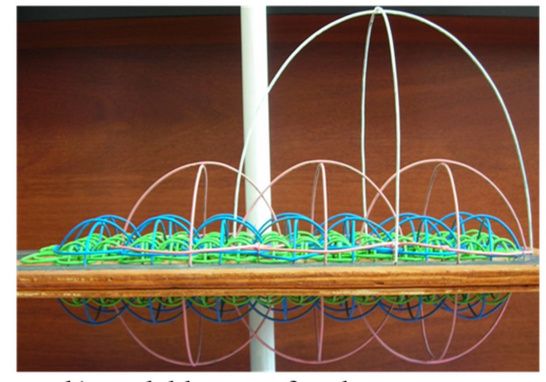

b) model layout of rock mass geomechanical process

Fig. 2. The concept of anthropogenic structuring of coal-bearing mass when mining a coal seam, taking into account the use of elastic energy and the combination of displacement archs [9]

The readings of pressure in power support props also have an undulation appearance, which undoubtedly reflects the processes in the supported rock mass.

Recalculating the pressure readings in power support props using formulas (1-3), determine the height of a rock layer, which exerts pressure on a support, assuming an average rock density of $2,5 \mathrm{t} / \mathrm{m}^{3}$ (Fig. 3).

The force response of power support props:

$$
F_{\text {ra }}=P_{r a .1} S_{r a .1}+P_{r a .2} S_{r a .2}
$$

The pressure of props distributed over the roof girder area:

$$
P_{o v}=F_{r a} / S_{o v}
$$

The height of the rock layer exerting pressure on the support:

$$
h_{r o}=P_{o v} / 0.025
$$

where $P_{\text {ra.l }}$ and $P_{\text {ra. }}$ - the fluid pressure in the power support props, MPa; $S_{r a .2}, S_{r a .2}$ - the area of the piston of the powered support props, $\mathrm{m}^{2} ; S_{o v}$ - the roof girder area, $\mathrm{m}^{2}$.

As can be seen from Figure 3, the rock layer thickness is limited to 45 meters. It can be said that this rock layer exerts direct pressure on the powered support. These ideas are fully consistent with the rock disintegration flowchart [9]. It is known that the bottom-hole part of a coal seam bears the main load of overlying rocks on a stope. The displacement arch base area, according to the flowchart, is a multiple of the length of a stope. 


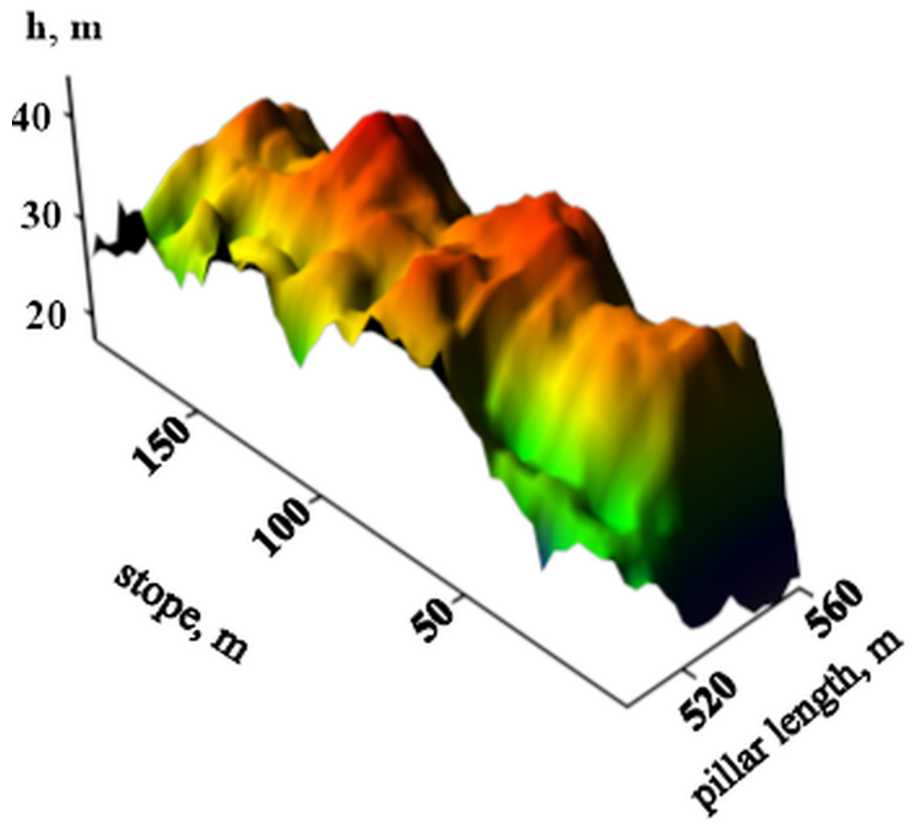

Fig. 3. The height of the rock layer that exerts pressure on the face support.

The geo-mechanical structuring flowchart shows the sequence of disintegrated rock displacement arching. Within the limits of the arches, the load will be equal to the weight of disturbed rocks in it, and this load falls on the face support and between the arches formed, rock pressure acts on a coal seam. It will be equal to the value of geostatic rock pressure plus bearing pressure, which is often 3-4 times higher than geostatic pressure. The magnitude of the sum of these pressures (geostatic plus bearing) depends on the coal seam depth, the stope advance rate, $\mathrm{m} /$ day, the strength of roof rocks. It is in the sum of geostatic and bearing pressure that is reflected in the state of a coal seam ahead of a stope and its effect is undulating. Similarly, the rock pressure effects, such as coal sloughing, and cutting resistance of a coal seam, also change in a wave-like manner along the length of a face. Also, gas content of a seam being mined depends on normal stresses [15], which will allow determining the geo-mechanical process parameters for a specific pillar taking area to forecast not only the negative rock pressure manifestations, but also methane release from all sources during coal mining, including methane release through the stope plane.

\section{Conclusion}

Thus, it is possible to determine the parameters of geo-mechanical stress undulation along the length of a face, timely and reasonable determination of areas of increased rock pressure on a coal seam and powered support, which will allow forecasting areas of the negative effect of the rock pressure along the length of a face, increasing the coal mining efficiency due to more accurate calculation of the load on a stope and the shearer output, specifying the forces of the working bodies of cutting machines when destructing a coal seam, selecting the face support according to bearing capacity, planning measures to eliminate the negative rock pressure effect in these areas, strengthen a selvedge to reduce the visible coal sloughing. Coal mining performance and safety will increase. 


\section{References}

1. A. V. Shadrin, V. I. Klishin, T Bulletin of the Science Center of VostNII on Industrial and Environmental Safety, 3, 31 (2017)

2. O. V. Tailakov, E. A. Utkaev, A. I. Smyslov, A. N. Kormin, KuzSTU Bulletin, 6, 13 (2014)

3. O. Yakobi, Rock pressure control practice (Moscow, Nedra, 1987)

4. H. Zhou, H. Liu, D. Hu, F. Zhang, F. Yang, J. Lu, European Journal of Environmental and Civil Engineering, 8, 954 (2016)

5. D. Y. Xuan, B. L. Wang, J. L. Xu, Int. J. Rock Mech. Min. Sci., 86, 235 (2016)

6. G. G. Litvinskiy, Collection of Scientific Papers of Donbass State Technical University, 3:46, 16 (2016)

7. A. L. Kasianenko, Problems of rock pressure, 2:29, 7 (2016)

8. M. V. Shinkevich, O. V. Bryuzgina, A. A. Ryabtsev, N. Yu. Nazarov, M.S. Plaksin, Coal, 11:979, 13 (2007)

9. M.V. Shinkevich, E.V. Leontieva, KuzSTU Bulletin, 3, 23 (2015)

10. M. Roiter, M. Roiter, V. Kurfyust, K. Mairkhover, Yu. Veksler, Journal of Mining Science, 2, 38 (2009)

11. N.V. Chekhmesterenko, Coal, 6, 3 (1992)

12. E. Z. Pozin, Resistance of coal to the destruction by cutting tools (Science, Moscow, 1972)

13. E. Z. Pozin, Destruction of rocks by mechanical methods (Science, Moscow, 1966)

14. E. Z. Pozin, Resistance of rocks to fracture during mining (Publishing House of the USSR Academy of Sciences, Moscow, 1962)

15. Yu. N. Malyshev, K. N. Trubetskoy, A.T. Ayruni Fundamental and applied methods for solving coal seams problems (IAGN, Moscow, 2000) 